\title{
Genetic and environmental effects on the timing of wing moult in the barnacle goose
}

\author{
KJELL LARSSON \\ Department of Zoology, Uppsala University, Villavägen 9, S-752 36 Uppsala, Sweden
}

\begin{abstract}
Genetic and environmental effects on the timing of wing moult were analysed in a breeding barnacle goose (Branta leucopsis) population recently established in the Baltic area. Start of wing moult of adults was found to be correlated with number of fledged young produced and start of wing moult of their breeding partners. Date of birth and age were not significantly correlated with start of wing moult although the length of the interval between hatching date of broods and start of wing moult was correlated with age. Repeatability estimates were significantly different from zero showing individual consistency of start of wing moult between years. Offspring-parent regressions and full-sib analyses yielded significant heritability estimates for start of wing moult. No indications of maternal effects were found. An especially high degree of resemblance between one-year-old full-sibs indicated the presence of a common environment effect on start of wing moult.
\end{abstract}

Keywords: Branta leucopsis, common environment, heritability, maternal effects, reproductive success, wing moult.

\section{Introduction}

The rate and direction at which quantitative traits can evolve in natural populations as a response to new selection pressures are dependent on the heritability and genetic correlations between traits (Lande, 1979; Falconer, 1981). In birds, many morphological traits have been found to be both highly heritable and genetically correlated with each other (Grant, 1986; Boag \& van Noordwijk, 1987; Larsson \& Forslund, 1992; Merilä \& Gustafsson, 1993). For traits more closely connected with lifetime reproductive success, such as clutch size, number of young produced, or life span, the few available heritability estimates are usually nonsignificant or low (Gustafsson, 1986; Mousseau \& Roff, 1987; Boag \& van Noordwijk, 1987; but see van Noordwijk et al., 1980; Schluter \& Gustafsson, 1993).

In recent years, studies have also started to focus on the inheritance of physiological and behavioural traits which might influence the timing of important events in the annual cycle (van Noordwijk et al., 1981; Berthold, 1989; Lambrecht \& Dias, 1993). For example, by studying captive birds from geographically separated populations, as well as their hybrids, Berthold (1989) found evidence for genetic effects on the control of moult, migratory restlessness and other migratory activities in several passerine bird species. Even though he was able to show that the differences between the studied bird populations had a genetic basis, this does not necessarily indicate that the phenotypic variation within populations is heritable. However, by using captive blackcaps (Sylvia atricapilla) from one partially migrating population in an artificial selection experiment, Berthold (1988) showed that the degree of migratory activity responded to selection. The realized heritability estimates obtained were high, suggesting that the intrapopulation variation observed under laboratory conditions to a large extent reflected genetic variation (Berthold, 1988). Because heritability estimates may be different under different environmental conditions (Gebhardt-Henrich \& van Noordwijk, 1991; Hoffmann \& Parsons, 1991; Larsson, 1993), a further step towards a better general understanding of the inheritance of timing of moult and other important activities in the annual cycle would be to analyse if such traits are also heritable under natural conditions.

In natural populations of birds, a significant degree of resemblance between related individuals may result not only from the effects of shared genes but also, for example, from the effects of a shared environment during growth or from maternal effects (Falconer, 1981; Larsson \& Forslund, 1992; Schluter \& Gustafsson, 1993; Gustafsson \& Merilä, 1994). 
Thus, to be able to conclude that an observed resemblance between relatives results from shared genes, it is necessary to analyse the importance of possible environmental causes of resemblance. Furthermore, knowledge about the effects of age, reproductive activities and other environmental and social circumstances on the studied traits is also of great importance in order to understand the causes for resemblance between relatives measured at different stages of life.

The aim of this paper is to examine genetic and environmental effects on start of wing moult in a population of barnacle geese (Branta leucopsis) breeding in the Baltic area, Sweden. It has been found previously that the mean date for start of wing moult in this 23-year-old temperate-breeding population differs greatly from the mean date for start of wing moult in Arctic-breeding barnacle goose populations (unpublished). It has also been found that the mean start of wing moult in the study population varies between years and correlates with the timing of breeding (unpublished).

Here, I extend the previous analyses, first, by examining how the start of wing moult in males and females correlates with environmental and social factors such as date of birth, age, breeding success, and start of wing moult in their breeding partners. Secondly, I analyse the within individual variation by calculating repeatability of start of wing moult for the same individuals in different years. Thirdly, I estimate heritability of start of wing moult using offspring-parent regressions and full-sib analyses. Fourthly, I analyse and discuss some possible pathways by which the obtained heritability estimates might have been inflated by a common environmental effect.

\section{Materials and methods}

Barnacle geese were studied on breeding and moulting sites along the coasts of the island of Gotland in the Baltic between 1984 and 1994. This Baltic-breeding barnacle goose population, which most probably originated from the Arctic Russian population of barnacle geese, has increased rapidly in numbers during the last 20 years (Larsson et al., 1988; Larsson \& Forslund, 1994). The largest colony in the Baltic area is situated on three small islands named Laus holmar $\left(57^{\circ} 17^{\prime} \mathrm{N} ; 18^{\circ} 45^{\prime} \mathrm{E}\right)$ and comprised about 1730 breeding pairs in 1994. Details of the number of breeding pairs and breeding success in the main colonies have been presented previously (Larsson et al., 1988; Larsson \& Forslund, 1994).
Flocks of adult and juvenile barnacle geese were captured on moulting localities by a rounding-up technique in the middle of July each year. Captured birds were individually marked with engraved coloured plastic leg rings which allowed individual identification at a distance. When determining the age of captured birds, I distinguished between adults, defined as birds one year old or older, and juveniles. Sex was determined by cloacal inspection (Owen, 1980).

The ninth primary feather, counted descendently (Ginn \& Melville, 1983), of captured moulting adult birds was measured to the nearest $1 \mathrm{~mm}$ by inserting a plastic ruler between the ninth and tenth primaries as deeply as possible and measuring the distance to the tip of the ninth primary. By comparing the lengths of the ninth primaries of 102 birds captured twice during a season it was estimated that the mean growth rate of this primary was $6.8 \mathrm{~mm} /$ day $(\mathrm{SD}=1.58, n=52)$ in females and $7.3 \mathrm{~mm} /$ day $(\mathrm{SD}=1.33, n=50)$ in males (unpublished). Start of wing moult was estimated by calculating the date at which the length of this primary was zero, using its length at capture and its sex-specific average growth rate. For birds which had dropped the old primary, but with the new primary not visible, the date of start of wing moult was defined as the day of capture. Of the captured birds, 2.7 per cent had not lost their old primaries on the day of capture. For these late-moulting birds, start of moult was defined as the day after the day of capture. The length of the new ninth primary of birds at capture varied considerably (mean $=62.5 \mathrm{~mm}, \mathrm{SD}=38.40$, range $0-275 \mathrm{~mm}, n=4722$, all years pooled). Therefore, possible confounding effects of individual variation in primary growth rate on the estimates of start of wing moult will most likely be small. Relative start of wing moult was calculated by subtracting yearspecific mean values of start of wing moult from the calculated individual values. The repeatability of relative start of wing moult was calculated for individuals measured in at least two different years (Lessells \& Boag, 1987).

Measures of reproductive performance, i.e. hatching date of broods and number of fledged young, were obtained for marked adults using observations made on the breeding grounds (Larsson \& Forslund, 1991, 1994). Hatching dates of broods of marked pairs were determined either by direct observations of pairs leaving their nest or by estimating the age of newly hatched young observed on nearby grazing grounds, and then backdating (for details see Larsson \& Forslund, 1991; Larsson et al., 1995). 
Relative hatching dates of broods were calculated by subtracting year-specific mean values of hatching dates of broods from the observed values. If a colour-marked juvenile was observed together with marked adults after catching (see below) I assumed that the date of birth of that juvenile was the same as the hatching date of the brood of those marked adults, which in turn had been determined earlier in the same season. Relative date of birth of an individual was defined as the difference, in days, between its date of birth and the yearly mean hatching date of broods.

The number of fledged young was defined as the number of young observed on the date closest to July 20 (within \pm 14 days) which is about one week before juveniles are able to fly. Complete breeding failure was sometimes recorded at an earlier date. Barnacle geese usually start breeding at two to four years of age (Owen, 1980; Larsson, 1992). One-yearold birds do not breed.

Family relationships were determined from observations of marked individuals on the breeding grounds and on the grazing grounds during the two weeks following catching. Grazing families were clearly distinguishable from other family groups. DNA-fingerprinting and direct observations have shown that intraspecific nest parasitism and adoption of young after hatching occur in this population resulting in about 17 per cent of the fledged young not being the true offspring of either their social mothers or fathers (Forslund \& Larsson, 1995; Larsson et al., 1995). No case of extra-pair fertilization has been detected (Larsson et al., 1995).

Heritability estimates $\left(h^{2}\right)$ for relative start of wing moult were obtained by regressing the mean values for adult offspring on female and male parents separately ( $h^{2}=$ twice the slope) and on mean values of both parents, i.e. midparent values $\left(h^{2}=\right.$ slope $)$ (Falconer, 1981). Differences between slopes of regressions were tested for significance by a homogeneity of slopes model (SAS Institute Inc., 1985). Heritability estimates were also obtained from analyses of adult full-sibs from broods of two or more sibs (Falconer, 1981). The presence of young not related to either their social mothers or fathers in broods (see above) is expected to deflate the heritability estimates. However, because extra-pair fertilizations seem to be absent or very rare the slopes of the offspring-father and offspring-mother regressions will be deflated by a similar magnitude. Several of the individuals included in the heritability analyses were measured in different years. In those cases only one randomly chosen measurement per individual was used. Some of the studied parents had broods in several years, but only one randomly chosen brood was included in the analyses. Thus, the same parents never appear more than once in offspring-parent regressions, and full-sib resemblance has been calculated from one brood only.

To analyse whether maternal effects or common environment effects were influencing the degree of resemblance between related individuals I compared heritability estimates obtained from different subsamples of birds. Higher heritability estimates from regressions of offspring on mothers than from regressions of offspring on fathers would indicate the presence of a maternal effect. Heritability estimates obtained from full-sib analysis are expected to be higher than estimates obtained from offspringparent regressions if there is dominance variance or if the rearing environment, which full-sibs share, affects start of wing moult of offspring (Falconer, 1981; Larsson \& Forslund, 1992). I also analysed the resemblance between related birds for which start of wing moult was measured at different ages. Separate analyses of one-year-old offspring, which never breed, and of offspring of four years old or more, which almost always make breeding attempts, may reveal possible confounding effects of timing of breeding on the heritability estimates obtained.

\section{Results}

\section{Start of wing moult in relation to date of birth and age}

Relative start of wing moult did not correlate with relative date of birth in either males or females $(r=0.06, n=83, P>0.5 ; r=0.02, n=102, P>0.8$, respectively). In an additional analysis, when only measurements of relative start of wing moult of one-year-old birds were used, the same result was found $(r=0.07, n=55, P>0.6$, males; $r=0.15$, $n=55, P>0.2$, females).

Relative start of wing moult was measured in birds of between one and ten years of age. The variation in mean relative start of wing moult among age classes was small compared to the variation between individuals within age classes (Fig. 1a). There was no significant relationship between relative start of wing moult and age for either males or females (Fig. 1a). For birds of two years old or more that bred and hatched young, there was a significant positive relationship between age and length of the interval between hatching date of broods and start of wing moult (Fig. 1b). This positive relationship in both males and females can be explained by older birds generally hatching their broods earlier than 
Fig. 1 Relative start of wing moult (a), and length of interval between hatching date of broods and start of wing moult (b) in relation to age of individual barnacle geese. Bars represent \pm 1 standard deviation. Sample sizes are given for males (upper line) and females (lower line) along the $x$-axis. Regression coefficients $(b)$ are based on mean values for males and females, respectively.
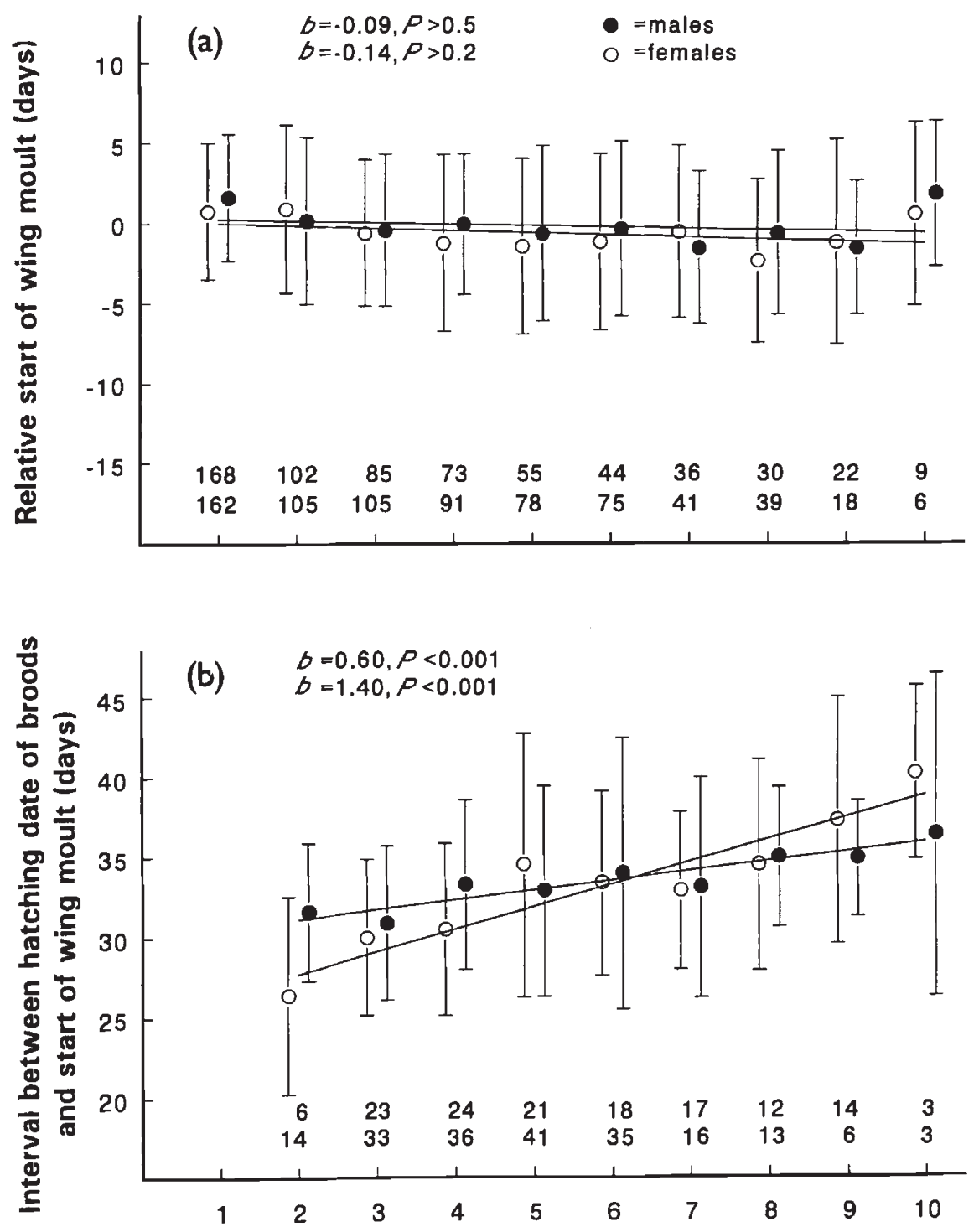

Age (years) younger birds $(r=-0.31, n=424, P<0.001$, males; $r=-0.36, n=759, P<0.001$, females; pooled data from 1985 to 1994) (Forslund \& Larsson, 1992).

\section{Start of wing moult in relation to brood size}

There was a significant relationship between brood size at fledging and relative start of wing moult in females (Fig. 2a). On average, females with larger broods started their wing moult earlier than females with smaller or no broods. No such relationship was found in males. The length of the interval between hatching date of broods and start of wing moult was significantly shorter for females with large broods than for females with small or no broods (Fig. 2b). In contrast, the length of this interval was significantly longer for males with large broods than for males with small or no broods (Fig. 2b). In males, the lack of correlation between relative start of wing moult and number of fledged young, despite the significant positive correlation between the length of the interval between brood hatching date and start of wing moult, and the number of fledged young, can be explained by the hatching date of broods being correlated with brood size at fledging $(r=-0.24, n=2531, P<0.001$, pooled data from 

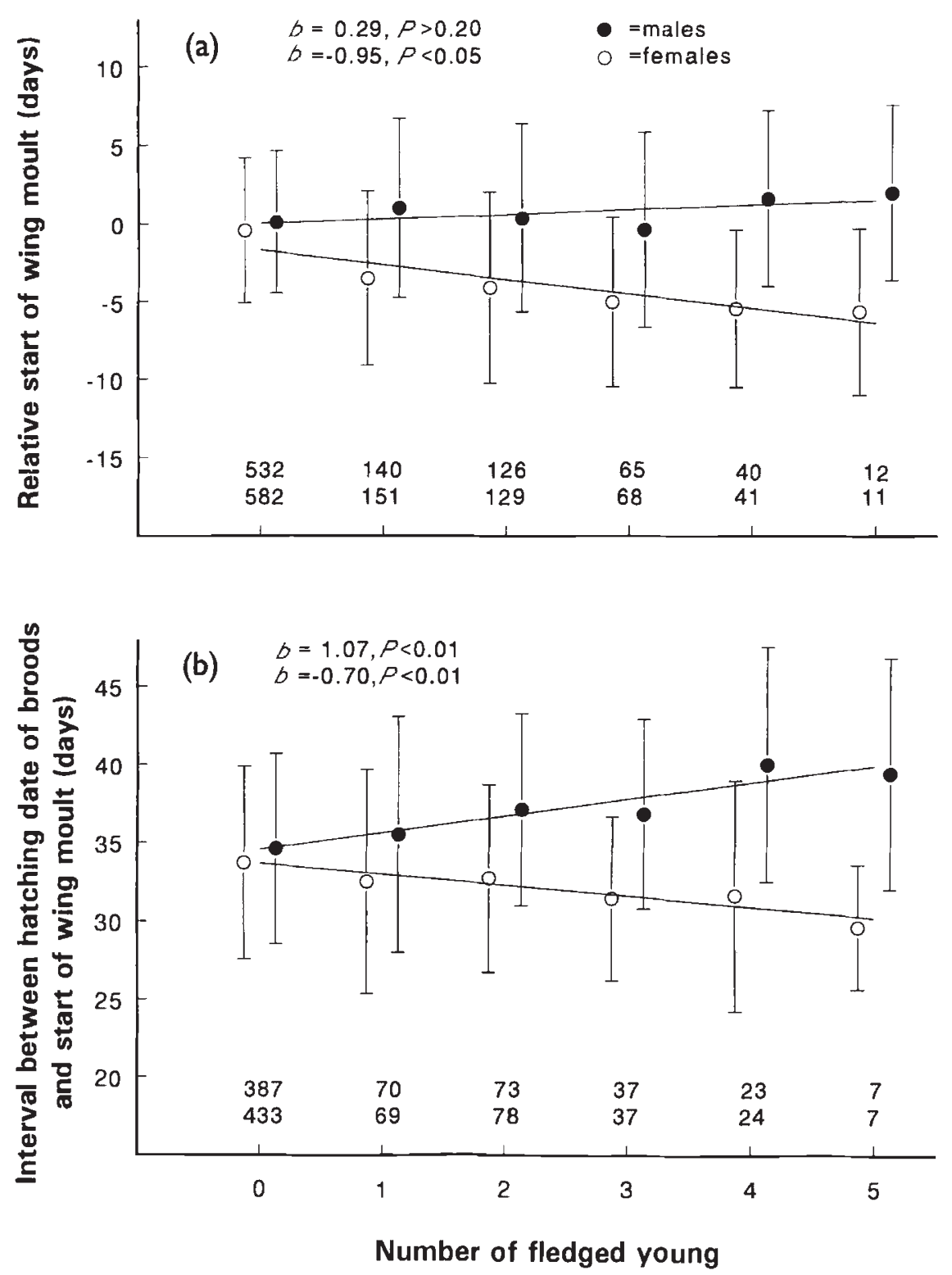

Fig. 2 Relative start of wing moult (a), and length of interval between hatching date of broods and start of wing moult (b), in relation to number of fledged young produced by barnacle geese. Bars represent \pm 1 standard deviation. Sample sizes are given for males (upper line) and females (lower line) along the $x$-axis. Regression coefficients $(b)$ are based on mean values for males and females, respectively.
1985 to 1994) (Forslund \& Larsson, 1992). Broods that are large at fledging have generally hatched earlier than smaller broods.

\section{Synchronization of start of wing moult within pairs}

The relative start of wing moult of partners within breeding pairs was positively correlated. The correlation between partners in pairs which failed to produce fledged young $(r=0.59, n=169, P<0.001)$ was significantly higher than the correlation between partners in breeding pairs which produced at least one fledged young $(r=0.20, n=283, \quad P<0.001)$
$(P<0.001$; test of homogeneity of the two correlation coefficients).

\section{Repeatability of start of wing moult}

Repeatability of relative start of wing moult was calculated for birds which were captured and measured in at least two different years. The first analysis, in which I included all birds which were measured twice, gave a repeatability estimate of 0.49 $\left(F_{1248,1249}=2.93, P<0.001\right)$. In two additional analyses, I selected measurements that had been made when the bird was one year old and not breeding 
and when the same bird was at least four years old. The repeatability estimate obtained when the first measurement was at one year of age and the second at four or more years of age was slightly lower (repeatability $=0.30, \quad F_{65,66}=1.84, \quad P<0.01$ ). The repeatability estimate obtained when both measurements were taken after four years of age was slightly higher $\left(\right.$ repeatability $\left.=0.58, F_{490,491}=3.71, P<0.001\right)$.

\section{Heritability of start of wing moult}

Heritability estimates obtained from offspringfather regressions and offspring-mother regressions, respectively, were not significantly different from each other (all $P>0.5$, homogeneity of slope tests) and similar to the estimates obtained from offspring-midparent regressions (Table 1). In two analyses I only included measurements of offspring that were taken when the offspring were one year old and at least four years old, respectively. These heritability estimates were of similar magnitude to the estimates obtained when data for all measured offspring were used (Table 1).

Heritability estimates were also obtained from full-sib analyses. When data from all full-sibs were used the heritability estimate was similar to the estimates obtained from the offspring-parent regressions (Table 1). When only full-sibs measured at one year of age were included in the analysis, the obtained heritability estimate was considerably higher (Table 1).

\section{Discussion}

In a previous study of this barnacle goose population, it was found that the mean date for start of wing moult varied between years, the mean start of wing moult being up to a week later in years when the mean hatching date of broods was late. It was also found that correlations between hatching date of broods and start of wing moult within years were slightly positive even though the length of the interval between hatching date of broods and start of wing moult was strongly negatively correlated with hatching dates of broods (unpublished). In this study, I found a significant relationship between number of fledged young and start of wing moult. I also found significant correlations between start of wing moult of breeding partners, the correlation being stronger in pairs which failed to produce fledged young than in pairs which did so successfully. Thus, the timing of start of wing moult in this Baltic barnacle goose population is clearly correlated with several different environmental and social factors.

Relationships between various environmental and social factors and start of wing moult have also been found in many other species of birds (Jenni \& Winkler, 1994; Kjellén, 1994). For example, in contrast to the situation in the present barnacle goose population, it is typically found that young nonbreeders and failed breeders moult considerably earlier than successful breeders (Owen, 1980; Jenni \& Winkler, 1994). Correlations between timing of wing moult and brood size have also previously been found, for example, in the Canada goose (Branta canadensis) and in the lesser snow goose (Chen caerulescens caerulescens). However, in contrast to the results from the present study, Lessells (1986) found that Canada goose females with larger broods started their wing moult later than females with smaller broods. Likewise, Williams et al. (1994) found that lesser snow geese that hatched four or more young and subsequently lost one or more of them during brood-rearing moulted significantly earlier than birds rearing all of their hatched young. Furthermore, by using brood size manipulation experiments, Siikamäki et al. (1994) found significant effects of brood size on timing of moult in female pied flycatchers (Ficedula hypoleuca). Various degrees of synchronization of wing moult between partners have also been reported before. In Arctic-

Table 1 Heritability estimates $\left(h^{2}\right)$ for relative start of wing moult in barnacle geese

\begin{tabular}{|c|c|c|c|c|c|c|c|c|c|}
\hline & \multicolumn{3}{|c|}{ All offspring } & \multicolumn{3}{|c|}{$\begin{array}{l}\text { Offspring measured when } \\
\text { one year old }\end{array}$} & \multicolumn{3}{|c|}{$\begin{array}{l}\text { Offspring measured when } \\
\text { four or more years old }\end{array}$} \\
\hline & $n$ & $h^{2} \pm \mathrm{SE}$ & $P$ & $n$ & $h^{2} \pm \mathrm{SE}$ & $P$ & $n$ & $h^{2} \pm \mathrm{SE}$ & $P$ \\
\hline Midparent-offspring & 141 & $0.23 \pm 0.08$ & $<0.01$ & 96 & $0.18 \pm 0.08$ & $<0.05$ & 57 & $0.33 \pm 0.14$ & $<0.05$ \\
\hline Father-offspring & 166 & $0.29 \pm 0.11$ & $<0.01$ & 107 & $0.22 \pm 0.11$ & 0.05 & 71 & $0.32 \pm 0.20$ & 0.10 \\
\hline Mother-offspring & 179 & $0.23 \pm 0.11$ & $<0.05$ & 114 & $0.23 \pm 0.11$ & 0.05 & 80 & $0.38 \pm 0.18$ & $<0.05$ \\
\hline Full-sib & 71 & $0.12 \pm 0.20$ & 0.26 & 35 & $0.86 \pm 0.26$ & $<0.01$ & 21 & $0.23 \pm 0.44$ & 0.30 \\
\hline
\end{tabular}

$n=$ number of families

(c) The Genetical Society of Great Britain, Heredity, 76, 100-107. 
breeding barnacle geese, Owen \& Ogilvie (1979) found, as I did in this study, that partners which failed to produce fledged young moulted more synchronously than partners which successfully produced fledged young.

Even though there is evidence which shows that traits such as timing of moult can be significantly affected by various environmental factors and social circumstances this does not necessarily mean that genetic factors are unimportant or that such traits would respond slowly to phenotypic selection. In this study, the repeatability estimates for relative start of wing moult were significantly different from zero and showed that the same individuals tended to start their wing moult at similar dates in different years. The repeatability estimates were especially high after the birds had reached the age of four. Thus, part of the total phenotypic variation observed in the population can be explained in terms of consistent differences between individuals. The heritability estimates for relative start of wing moult were also generally significantly different from zero. This indicates that part of the phenotypic variation within the population reflects additive genetic variation. The heritability estimates obtained from offspring-father regressions were not significantly different from those obtained from offspring-mother regressions. Hence, maternal or paternal effects on this trait seemed to be absent or weak.

The heritability estimate obtained from analyses of measurements of one-year-old full-sibs was considerably higher than estimates obtained from analyses of older full-sibs and from offspring-parent regressions. Therefore, it is likely that some component of the environment shared by full-sibs affected the timing of wing moult when the birds were one year old, but that this effect disappeared or became overshadowed by other factors later in life. In some bird species, moulting has been found to begin exactly one year after birth and subsequently at about 12 month intervals (Gwinner, 1986). It is therefore possible that the annual moulting rhythm might be affected by seasonally varying external factors to which an individual is exposed during ontogeny. However, there were no significant correlations between relative date of birth and relative start of wing moult in either one-year-old or older birds. Thus, the high degree of resemblance between one-year-old full-sibs cannot be explained by effects of date of birth. Because barnacle goose families do not normally split up until the following spring (Black \& Owen, 1989) it is possible, for example, that factors such as choice of feeding sites or food intake, which probably are more similar in full-sibs than in randomly chosen individuals, may have affected the timing of the first wing moult in one-year-old birds.

In conclusion, this study showed that the large individual variation in timing of start of wing moult can be explained to a considerable extent in terms of external environmental variation and social circumstances. However, my comparisons of related adult individuals also showed that a significant part of the phenotypic variation most probably can be ascribed to additive genetic variation. Thus, if the timing of wing moult influences the lifetime reproductive success of individuals one can expect evolutionary changes in the date of start of wing moult in this population. The mean start of the wing moult of Baltic-breeding barnacle geese occurs about three weeks earlier than that of Arctic-breeding barnacle geese, from which the Baltic birds most probably originated about 23 years ago (unpublished). Thus, it is possible that at least part of the observed difference in mean date of start of wing moult actually represents a recent microevolutionary change in the Baltic population. However, to be able to confirm that these population differences indeed reflect genetic differences, other types of analysis, for example transplant experiments (cf. Rhymer, 1992), are needed.

\section{Acknowledgements}

I thank Pär Forslund, Juha Merilä, Ben Sheldon and Staffan Ulfstrand for discussions and comments on the manuscript. Financial support was provided by the Swedish Natural Science Research Council, Olle och Signhild Engkvist Stiftelser, and the Swedish Environmental Protection Agency.

\section{References}

BERTHOLD, P. 1988. Evolutionary aspects of migratory behavior in European warblers. J. Evol. Biol., 1, 195-209.

BERTHOLD, P. 1989. Genetics of migration. In: Gwinner, E. (ed.) Bird Migration, pp. 269-280. Springer-Verlag, Berlin/Heidelberg.

BLACK, J. M. AND OWEN, M. 1989. Parent-offspring relationships in wintering barnacle geese. Anim. Behav., 37, 187-198.

BOAG, P. T. AND VAN NOORDWIJK, A. J. 1987. Quantitative Genetics. In: Cooke, F. and Buckley, P. A (eds) Avian Genetics, pp. 45-78. Academic Press, London.

FALCONER, D. S. 1981. Introduction to Quantitative Genetics, 2nd edn. Longman, New York.

FORSLUND, P. AND LARSSON, K. 1992. Age-related reproductive success in the barnacle goose. J. Anim. Ecol., 
61, 195-204.

FORSLUND, P. AND LARSSON, K. 1995. Intra-specific nest parasitism in the barnacle goose: behavioural tactics of parasites and hosts. Anim. Behav., 50, 509-517.

GEBHARDT-HENRICH, S. G. AND VAN NOORDWIJK, A. J. 1991. Nestling growth in the Great Tit I. Heritability estimates under different environmental conditions. $J$. Evol. Biol., 3, 341-362.

GINN, H. B. AND MELVILLE, D. s. 1983. Moult in Birds. The British Trust for Ornithology, Tring, Herts, UK.

GRANT, P. R. 1986. Ecology and Evolution of Darwin's Finches. Princeton University Press, Princeton, NJ

GUSTAFSSON, L. 1986. Lifetime reproductive success and heritability: empirical support for Fisher's fundamental theorem. Am. Nat., 128, 761-764.

GUSTAFSSON, L. AND MERILÄ, J. 1994. Foster parent experiment reveals no genotype-environment correlation in the external morphology of Ficedula albicollis, the collared flycatcher. Heredity, 73, 124-129.

GWINNER, E. 1986. Circannual Rhythms. Springer-Verlag, Berlin.

HOFFMANN, A. A. AND PARSONS, P. A. 1991. Evolutionary Genetics and Environmental Stress. Oxford University Press, Oxford.

JENN1, L. AND w1NKLER, R. 1994. Moult and Aging of European Passerines. Academic Press, London.

KJELLÉN, N. 1994. Moult in relation to migration in birds a review. Ornis Svecica, 4, 1-24.

LAMBRECHTS, M. M. AND DIAS, P. C. 1993. Differences in the onset of laying between island and mainland Mediterrannean Blue Tits Parus caeruleus: phenotypic plasticity or genetic differences? Ibis, 135, 451-455.

LANDE, R. 1979. Quantitative genetic analysis of multivariate evolution, applied to brain:body size allometry. Evolution, 33, 402-416.

LARSSON, K. 1992. Ecological and quantitative genetic processes in a population of the Barnacle Goose (Branta leucopsis). Comprehensive Summaries of Uppsala Dissertations from the Faculty of Science (no. 382). Acta Universitatis Upsaliensis. Uppsala University, Sweden.

LARSSON, K. 1993. Inheritance of body size in the Barnacle Goose under different environmental conditions. $J$. Evol. Biol., 6, 195-208.

LARSSON, K. AND FORSLUND, P. 1991. Environmentally induced morphological variation in the Barnacle Goose, Branta leucopsis. J. Evol. Biol., 4, 619-636.

LARSSON, K. AND FORSLUND, P. 1992. Genetic and social inheritance of body size and egg size in the barnacle goose (Branta leucopsis). Evolution, 46, 235-244.
LARSSON, K. AND FORSLUND, P. 1994. Population dynamics of the barnacle goose Branta leucopsis in the Baltic area: density-dependent effects on reproduction. $J$. Anim. Ecol., 63, 954-962.

LARSSON, K., FORSLUND, P., GUSTAFSSON, L. AND EBBINGE, B. s. 1988. From the high Arctic to the Baltic: the successful establishment of a Barnacle Goose Branta leucopsis population on Gotland, Sweden. Ornis Scand., 19, 182-189.

LARSSON, K., TEGELSTRÖM, H. AND FORSLUND, P. 1995. Intraspecific nest parasitism and adoption of young in the barnacle goose: effects on survival and reproductive performance. Anim. Behav., in press.

LESSELLS, C. M. 1986. Brood size in Canada geese: a manipulation experiment. J. Anim. Ecol., 55, 669-689.

LESSELLS, C. M. AND BOAG, P. T. 1987. Unrepeatable repeatabilities a common mistake. $A u k, 104,116-121$.

MERILÄ, J. AND GUSTAFSSON, L. 1993. Inheritance of size and shape in a natural population of collared flycatchers, Ficedula albicollis. J. Evol. Biol., 6, 375-395.

MOUSSEAU, T. A. AND ROFF, D. A. 1987. Natural selection and the heritability of fitness components. Heredity, 59, 181-197.

VAN NOORDWIJK, A. J., VAN BALEN, J. H. AND SCHARLOO, w. 1980. Heritability of ecologically important traits in the great tit. Ardea, 68, 193-203.

VAN NOORDWIJK, A. J., VAN BALEN, J. H. AND SCHARLOO, W. 1981. Genetic variation in the timing of reproduction in the Great Tit. Oecologia , 49, 158-166.

oWEN, M. 1980. Wild Geese of the World. Batsford, London.

OWEN, M. AND OGILVIE, M. A. 1979. Wing moult and weights of barnacle geese in Spitsbergen. Condor, 81, $42-52$.

RHYMER, J. 1992. An experimental study of geographic variation in avian growth and development. J. Evol. Biol., 5, 289-306.

SAS INSTITUTE INC. 1985. SAS User's Guide: Statistics, Version 5 Edition. SAS Institute Inc., Cary, NC.

SCHLUTER, D. AND GUSTAFsSON, L. 1993. Maternal inheritance of condition and clutch size in the collared flycatcher. Evolution, 47, 658-667.

SIIKAMÄKI, P., HOVI, M. AND RÄTTI, O. 1994. A trade-off between current reproduction and moult in the Pied Flycatcher - an experiment. Funct. Ecol, , 8, 587-593.

WILliAMS, T. D., LOONEN, M. J. J. E. AND COOKE, F. 1994. Fitness consequences of parental behaviour in relation to offspring number in a precocial species: the lesser snow goose. $A u k, 111,563-572$. 